\title{
Effect of Elaborateness of Apology on Subsequent Disciplinary Action Considering Outcome Severity and Favorable Reputation as Moderators
}

\author{
Jonathan C. Lee' ${ }^{1}$, Hyejung Chang $^{2}$ \\ 'University of Windsor Odette School of Business, Windsor, ON, Canada \\ ${ }^{2}$ Kyung Hee University School of Management, Seoul, Korea
}

Objectives: Both managers and scholars have strong reason to understand the human response of apology in different degrees and under different circumstances as a possible influencer of punishment of employees for violating workplace rules. The purpose of this study is to investigate the effect of apology on subsequent disciplinary action, considering different levels of elaborateness of apology, severity of outcomes, and favorableness of reputation.

Methods: A $3 \times 2 \times 2$ between subject factorial design experiment was conducted with 262 participants. The dependent variable was discipline, and three independent variables included the elaborateness of apology, the offender's reputation, and the severity of outcome resulting from the violation. Collected data was analyzed using ANOVA and planned comparisons.

Results: The claim that apology leads to less punishment was partially supported. Although there was no statistically significant support for an apology's effect on a 6-item composite measure of disciplinary action, the effects of apology on individual items such as dismissal showed significance. There was also support for the effects of severity of outcome and reputation of the offender on the level of disciplinary action recommended.

Conclusions: The results of the present study demonstrate that the issue of apology's effect on discipline is more complex than once thought. Thus greater consideration should be taken in efforts to achieve a better understanding of its effects.

Key Words: Apology, Disciplinary Action, Violation, Reputation, Outcome Severity

\section{Introduction}

In all human relationships, when a person transgresses against a rule, offending another, he or she is likely to apologize. The

Received: May 21, 2021 Revised: Jun 6, 2021 Accepted: Jun 27, 2021 Corresponding author: Hyejung Chang

Kyung Hee University School of Management, 1 Hoegi-Dong Dongdaemoon$\mathrm{Gu}$, Seoul 02447, Korea

Tel: +82-2-961-9432, Fax: +82-2-961-0515, E-mail: hjchang@khu.ac.kr

This is an Open Access article distributed under the terms of the Creative Commons Attribution Non-Commercial License (http://creativecommons.org/licenses/ by-nc/4.0/) which permits unrestricted non-commercial use, distribution, and reproduction in any medium, provided the original work is properly cited.

Copyright $(\odot) 2021$ Korean Association for Business Communication. apology may serve to at least partially right the wrong. It may also lower the probability of an aggressive response on the part of the person offended. Given the use of punishment for workplace infractions, both managers and scholars have strong reason to understand its determinants. In addition to other determinants, it is worthwhile to consider the common human response of apology in different degrees and under different circumstances as a possible influencer of punishment of employees for violating workplace rules.

Apology is the acknowledgement of blameworthiness and expression of regret for a transgression against a rule or a norm (Darby \& Schlenker, 1989; Schlenker, 1980). The parties to the apology are the offender (or, "violator") who makes the apology 
and the receiver of the apology. Where a workplace rule has been violated by an offender who is an employee the person offended would usually be the employee's supervisor.

Apologies perform several different functions, e.g. acknowledging that rules have been violated, recognizing the value of the rules, and acknowledging the interpersonal obligations involved (Bataineh \& Bataineh, 2006; Darby \& Schlenker, 1989). Apologies may have a number of meaningful effects on the offender and the offended, such as: (a) when the offender publicly acknowledges her responsibility, it may restore the offended's self-esteem and social identity; (b) when the offender offers help or asks for forgiveness, it may be interpreted as expressing respect for the offended; (c) when the offender apologizes with self-disapproval, it may be for impression management; and (d) when the offender subjects herself to public disgrace or expresses remorse, this can be taken as a form of self-punishment that restores social justice (Christopher, Marek, \& May, 2003; Leunissen, De Cremer, \& Reinders Folmer, 2012; Ohbuchi, Kameda, \& Agarie, 1989).

Strategies by which both child and adult offenders attempt to exert control over how others perceive the offender have been noted (Bataineh \& Bataineh, 2006; Harrell, 1979; Goffman \& Manning, 1971; Schlenker \& Darby, 1981; Schumann, 2014). Apologies stem from the human socialization process (Aronfreed, 1968; Burton, MacCoby, \& Allinsmith, 1961), and Langer (1978) notes that apologies and remorse may evoke an automatic, scripted reaction. For socialized individuals, the apology-forgiveness sequence is so ingrained that the tendency to respond positively to an apology may be strong and subsequently beneficial to the user. Another way of explaining the forgiveness response is that it is based upon an innate inhibition against harming an individual who engages in self-abasement (Karremans \& Van Lange, 2004; Wheeler, 1985).

It is evident from past studies that the expression of apology may lead to less punishment. However, according to a number of researchers such as O'Malley and Greenberg (1983) and Schlenker (1980), apology sometimes does not lead to less punishment. Unfortunately, the explanations for the inconsistent and even anomalous results of these studies lack empirical support to make their suggestions compelling. It remains unclear under what circumstances the expression of apology is effective in reducing punishment.

The previous failure to deal convincingly with the above questions stems from an apparent lack of awareness of a limitation of these studies: the conditions studied have been restricted to the dichotomous alternatives of "no apology" and "apology," without considering varying degrees of apology. The idea that an apology can be expressed in varying degrees is not new
(Schlenker \& Darby, 1981). However, no one has yet examined the possible effects of varying degrees of apology (Schlenker \& Darby refer to this as "elaborateness of apology") on discipline. By examining the effects of elaborateness of apology on discipline we can begin to examine more specifically under what circumstances the expression of apology is effective in reducing punishment (Lee, 1999).

Two moderators that have been suggested as influencing the relationship between apology and discipline are: (1) severity of outcome of the violations (Gavin, Green, \& Fairhurst 1995; O’Malley \& Greenberg, 1983); and, (2) favorableness of reputation of the offender as perceived by the offended (Darby \& Schlenker, 1989; Jones \& Wortman, 1973; Schlenker, 1980). This study investigates the effect of apology on subsequent disciplinary action, considering different levels of elaborateness of apology, severity of outcomes, and favorableness of reputation.

\section{Theoretical Framework}

\section{Definition of Variables}

\section{Elaborateness of Apology}

Three levels of elaborateness are considered for apology as follows:

- No apology: no action,

- Simple apology: simple apology is measured as the offender saying, "I'm sorry, I feel badly about this" (Darby \& Schlenker, 1982), and

- Elaborate apology: this value is towards the "maximum" end of the continuum, and includes all of the following: (1) self-castigation; (2) expressing a desire to compensate for damages; and (3) direct attempts at obtaining forgiveness (Schlenker \& Darby, 1981).

\section{Severity of the Violation}

In this study, manipulation involving the severity of the violation is based on the outcome of the violation. A "minor outcome" involves a damaged car with repair cost of \$30-40; in a "major outcome" condition, the repair to the car costs $\$ 4,000-4,500$.

\section{Favorableness of Reputation}

Favorableness of reputation is operationalized based on a definition provided by Tsui (1984). Tsuis definition is based on role theory which suggests that a person with a good reputation is someone who has successfully performed their set of role expectations. Based on the above definitions, this study will define the employee's reputation as follows:

- Bad reputation: offender is a person of dishonorable character and viewed by fellow co-workers as someone who 
lacked integrity, and

- Good reputation: offender is a person of honorable character and viewed by fellow co-workers as honest.

\section{Definition of Interactions}

In addition to the three independent variables, the interaction effects of the elaborateness of the apology and the severity of the outcome are systematically manipulated to produce "goodness of fit" or lack thereof. It is expected that the more severe the outcome, the greater the "fitting" apology. An offense involving a "major outcome" is expected to require an elaborate expression of apology to be perceived as "satisfactory," while a simple expression of apology is expected to be perceived as "inadequate." The definitions are:

- Inadequate: a weak apology that is less than satisfactory, i.e., not sufficiently elaborate given the severity of the violation,

- Satisfactory: either a simple or an elaborate expression of apology that is satisfactory given the severity of the violation, and

- Excessive: a strong expression of apology that is "too much" given the severity of the violation.

\section{Hypotheses}

Seven hypotheses were examined in this study, based on the systematic research testifying to both the effectiveness of an apology and ineffectiveness of an apology on the level of punishment (Fehr, Gelfand, \& Nag, 2010; Lee, 1999).

\section{Expression of Apology}

Based on literature reviewed, it is hypothesized that:

- Hypothesis 1: The more elaborate the apology, the less the punishment will be.

\section{Seriousness of the Offense}

Past studies suggest that one of the ways in which we can measure the seriousness of the offense is by looking at the severity of the outcome. Thus:

- Hypothesis 2: The greater the severity of the outcome, the greater the punishment will be.

\section{Offender's Reputation}

An offender's good reputation will be perceived as congruent with the apology expressed. In contrast, a bad reputation will be viewed as incongruent with the apology, thus undermining the apology's impact. Thus:

- Hypothesis 3: When the offender's reputation is favorable, the punishment will be less than when it is unfavorable.

\section{Elaborateness of Apology and Outcome}

It is predicted that offenders who apologize "satisfactorily" and with "goodness of fit" will be punished less than those who apologize inadequately, excessively, or not at all. Interactions under which "satisfactory" apologies will be achieved are: a "simple apology" expressed under the condition of "minor outcome" (C) and an "elaborate apology" expressed under "major outcome" (B). The "A" in Figure 1 (top) represents an apology that is inadequate, and " $\mathrm{D}$ " represents an apology that is excessive. Under the last condition, it is expected that increased elaborateness of apology will reduce punishment less than with a major outcome. Thus:

- Hypothesis 4: The effects of elaborateness of apology are moderated by severity of outcome such that the difference between a simple and elaborate apology is greater when the outcome is major than when it is minor.

\section{Elaborateness of Apology and Reputation}

Good reputation may enhance an apology because the positive character of the offender is congruent with it. Conversely, a bad reputation may undermine an apology because the negative offender's character is seen as incongruent with the apology. As shown in Figure 1 (bottom), the impact of elaborateness of apology on punishment is less when the offender has a bad reputation than when the offender has a good reputation.

- Hypothesis 5: The effects of elaborateness of apology on punishment are moderated by the reputation of the offender such that the difference between a simple and elaborate apology is greater when the offender has a good reputation than a bad reputation.

\section{Partial 3-Way Interaction of Elaborateness of Apology, Reputation and Outcome}

Bad reputation may undermine the apology. Jones and Wortman (1973) argued that an excessive apology expressed by an offender may be perceived as intentionally trying to ingratiate in order merely to obtain pardon. In Figure 2(a), the interaction under which an "excessive apology" is perceived as manipulative is when an "elaborate apology" is expressed under "minor outcome" (B and D).

- Hypothesis 6: Under minor outcome condition, the negative impact of an elaborate apology is greater when the offender has a bad reputation than when the offender has a good reputation.

Although no prior studies considered inadequate apologies, it is possible to speculate on the outcome of an inadequate apology using equity theory. An offender with a good reputation who appears sorry and apologizes will likely be treated as someone who is aware of her responsibility for harm done. For an 

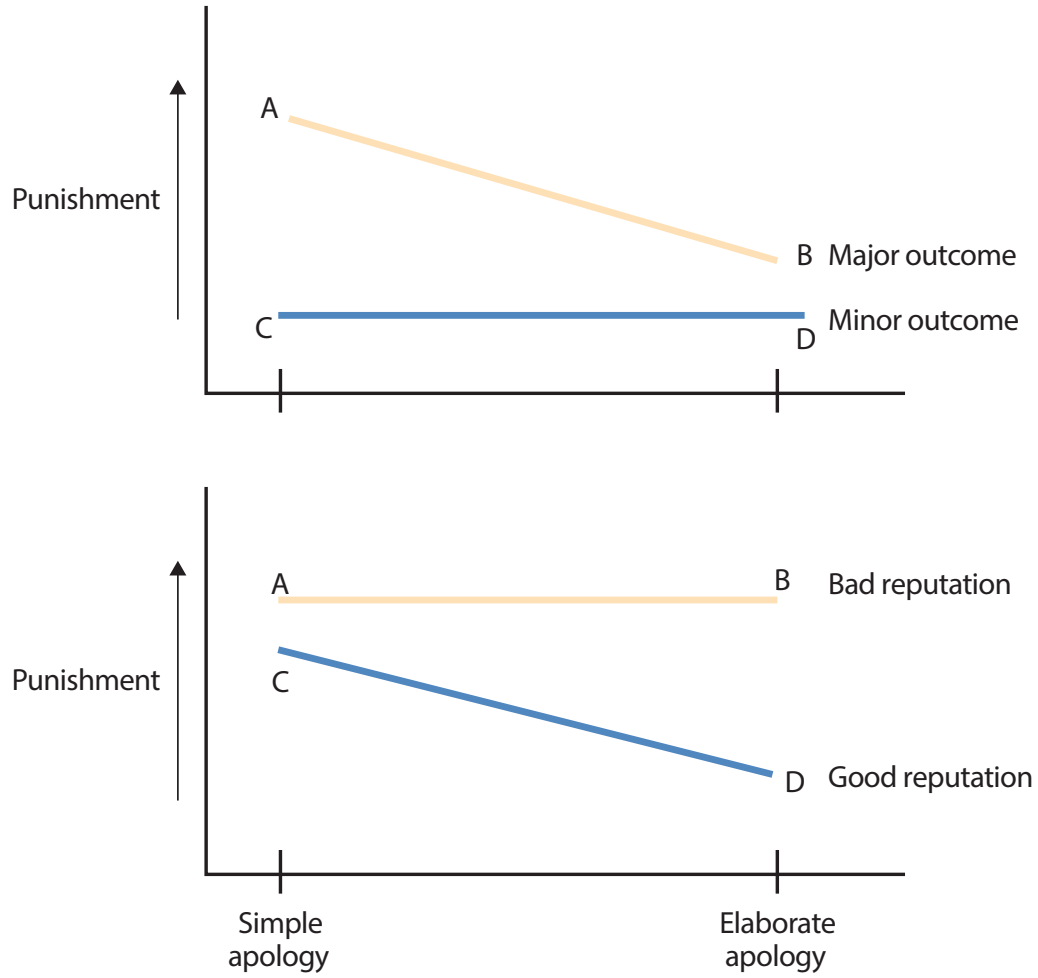

Figure 1. Elaborateness of apology with outcome and reputation.

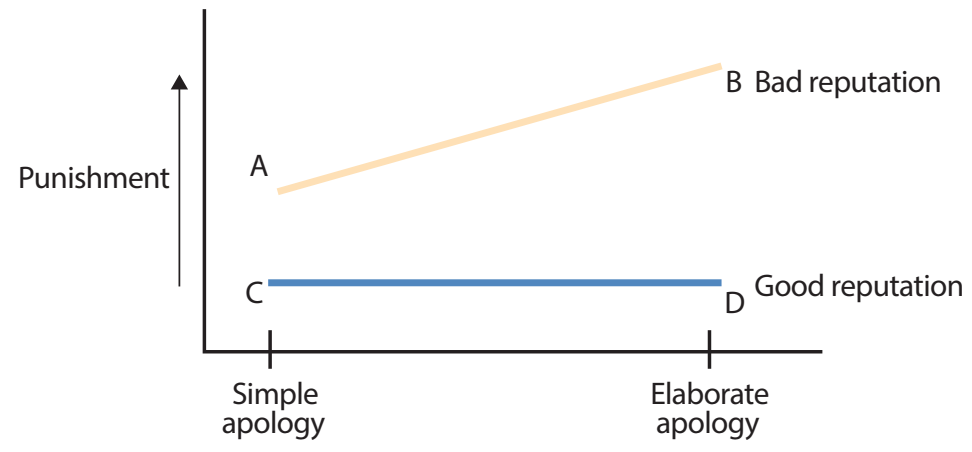

(a) Minor outcome
A

B Bad reputation<smiles>[CH]1[CH]CC1</smiles>

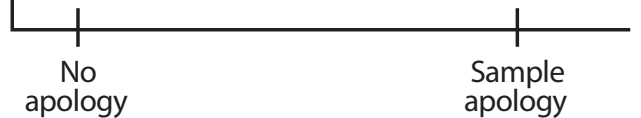

(b) Major outcome

Figure 2. Interaction of apology and reputation in different levels of outcome severity.

offender with a bad reputation, a less than satisfactory apology will not result in less punishment than no apology since the expression of apology will have been undermined by the negative character of the offender. In terms of Figure 2(b), this implies that where the outcome is major, punishment will not decline as one moves from $\mathrm{A}$ to $\mathrm{B}$ where the reputation is bad, but will decline substantially from $\mathrm{C}$ to $\mathrm{D}$ where reputation is good. Based on the previous arguments, it is also hypothesized that:

- Hypothesis 7: Under major outcome condition, the positive impact of a simple apology versus no apology is greater when the offender has a good reputation than when the offender has a bad reputation.

\section{Method}

\section{Study Design and Subjects}

The study design was a $3 \times 2 \times 2$ between subject factorial with the elaborateness of apology, the offender's reputation, and the severity of outcome resulting from the violation as the three independent variables. The dependent variable was discipline. 
Two hundred and sixty-two undergraduate students participated in this study.

\section{Procedure}

Subjects read a report on a work rule violation committed by an employee. The report described the violation, the behavior of and some background information on the offender. The experimenter explained that this report had been sent to them for a recommendation for the most appropriate way to deal with the offender. The reports were modified versions of the Rosen and Jerdee (1974) and O’Malley and Greenberg (1983) scenarios.

\section{Measurement}

\section{Manipulation Checks:}

The instrument contained manipulation checks for degree of apology, severity of outcome, and the offender's reputation. Subjects felt that offenders who engaged in elaborate apology were more apologetic than those who engaged in simple or no apology $(F=318.54, p<.001$, Tukey procedure yielded significance at $p<.05)$. Respondents felt that the offender who had a good reputation had better reputation $(\bar{x}=6.20)$ than the offender who was depicted as having a bad reputation $(\bar{x}=1.96, t=35.21, p<$ .001). Manipulations for major and minor outcomes were also successful at $p<.001$.

\section{Dependent Measures:}

Severity of discipline recommended by respondents was measured by statements describing six disciplinary actions on a Likert-type scale. Six items were choices given to the subjects following a disciplinary action statement such as "I would dismiss the offender." Low coefficient alpha $(\alpha=.63)$ indicated that a composite measure was problematic. An attempt was made to dichotomize the responses on the items on the Likert scale, based on a Guttman procedure with a cutoff score of two. This makes sense conceptually because it separates those who agree from those who do not. The Coefficient of Reproducibility was .91 for the cutoff score. The composites of the dichotomized scale and the subsequent averaging of the total "created" a dependent variable, Discipline.

\section{Data Analyses}

Analysis involved ANOVA (Analysis of Variance) and planned comparisons. It was anticipated that the overall $\mathrm{F}$ test would be significant and the main effects would support Hypotheses 1, 2 and 3. Since a significant F only reveals that the overall hypothesis of equality of means is rejected, in order to test the remaining hypotheses further tests were required to pinpoint which means were not equal (Kirk, 1982). The subjects' responses to three independent variables were placed in a data matrix. By examining mean response values in the twelve cells, Hypotheses 4, 5, 6, and 7 were tested. Thus, four orthogonal planned comparisons involving complex contrasts were performed on the dependent measure.

Explicitly, Hypothesis 4 was tested with a planned comparison as follows: the difference between the means A (Simple Apology/Major Outcome) and B (Elaborate Apology/Major Outcome) was compared to the difference between the means C (Simple Apology/Minor Outcome) and D (Elaborate Apology/Minor Outcome). We expected: $(\mathrm{A}-\mathrm{B})>(\mathrm{C}-\mathrm{D})$ (Figure 1). The second planned comparison tested Hypothesis 5 which involved looking at the interaction effects of elaborateness of apology and offender's reputation. The difference between the means A (Simple Apology/Bad Reputation) and B (Elaborate Apology/Bad Reputation) was compared to the difference between the means C (Simple Apology/Good Reputation) and D (Elaborate Apology/Good Reputation), and we expected: (A-B) $<(\mathrm{C}-\mathrm{D})$ (Figure 1). Hypotheses 6 and 7 interactions are shown in Figure 2. And for Hypotheses 6 and 7, we expected (B-A) > $(\mathrm{D}-\mathrm{C})$ and $(\mathrm{A}-\mathrm{B})<(\mathrm{C}-\mathrm{D})$, respectively.

In addition to the examination of the composite variable Discipline, items were examined separately for each hypothesis. For testing Hypotheses 1-3 on each variable, ANOVA was used. Four orthogonal planned comparisons involving complex contrasts were performed on the six disciplinary items to test Hypotheses 4-7.

\section{Results}

\section{Composite Discipline as a Dependent Variable}

\section{Apology-Outcome-Reputation}

Hypothesis 1 predicts that the more elaborate the apology, the less the punishment will be. As shown in Table 1, the results of ANOVA failed to support the hypothesis $(F=.13, p=.875)$. Almost no difference is shown in the trends for treatment variable apology: $\bar{x}=.46$ for no apology, $\bar{x}=.45$ for simple apology, and $\bar{x}=.46$ for elaborate apology (Figure 3a). However, results of the ANOVA show support for Hypothesis $2(F=11.63, p<.001)$. As shown in Figure $3 \mathrm{~b}$, subjects were less likely to recommend disciplinary action under minor outcome condition than under the major outcome condition. Hypothesis 3 predicts that when the offender's reputation is favorable the punishment will be less than when the offender's reputation is unfavorable. This was tested by the main effects of the treatment variable Reputation on the dependent variable Discipline Results show support for Hypothesis $3(F=9.41, p=.002)$. For good reputation, respondents were less likely to recommend disciplinary action, as shown in Figure 3c. 
Table 1. Results of analyses of variance: Discipline as a dependent variable

\begin{tabular}{|c|c|c|c|c|c|}
\hline Source of variation & Sum of squares & df & Mean square & $F$-value & $p$-value \\
\hline Apology & .012 & 2 & .006 & .13 & .875 \\
\hline Outcome & .570 & 1 & .570 & 11.63 & $<.001$ \\
\hline Reputation & .461 & 1 & .461 & 9.41 & .002 \\
\hline Apology $\times$ Outcome & .014 & 2 & .007 & .15 & .863 \\
\hline Apology $\times$ Reputation & .063 & 2 & .032 & .65 & .523 \\
\hline Outcome $\times$ Reputation & .024 & 1 & .024 & .50 & .479 \\
\hline Apology $\times$ Outcome $\times$ Reputation & .127 & 2 & .063 & 1.29 & .276 \\
\hline
\end{tabular}

Discipline

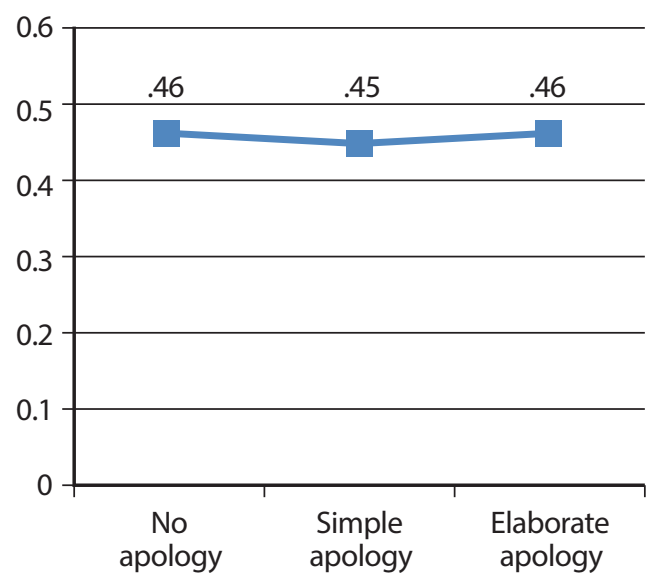

(a) Apology

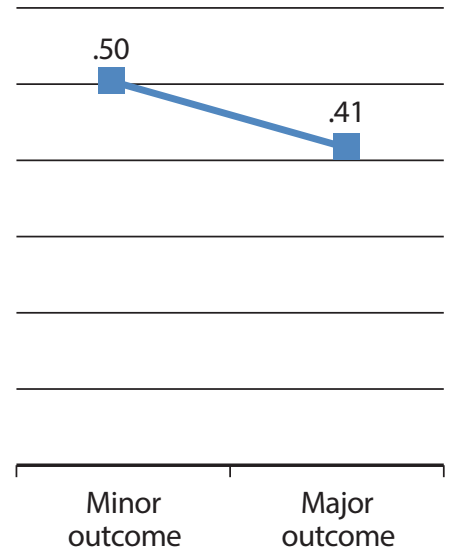

(b) Outcome

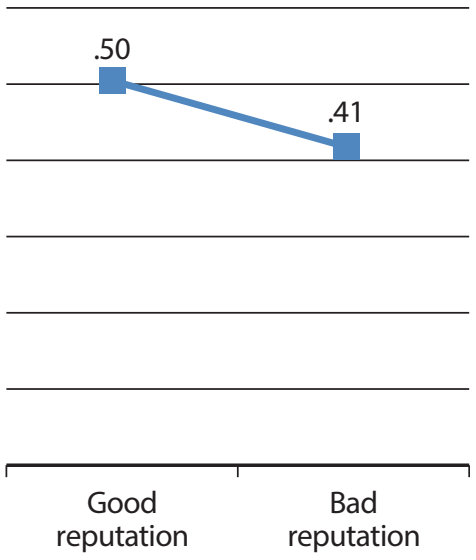

(c) Reputation

Figure 3. Effects of apology, outcome severity, and reputation on discipline.

\section{Elaborateness of Apology with Outcome and Reputation}

This analysis tested whether the effectiveness of apology is dependent upon fit between the elaborateness of the apology and the severity of outcome. Hypothesis 4 predicts that the effects are moderated by severity of outcome such that the difference in the level of punishment between a simple and elaborate apology is greater when the outcome is major than when it is minor. The result indicates no significant difference for interaction Apology by Outcome on Discipline $(F=.15, p=.863)$. Under both outcomes, as the apology went from simple to elaborate, respondents were less likely to recommend disciplinary action (Figure 4a). A complex contrast was used to test Hypothesis 5. The result indicated no significant difference for Apology by Reputation on Discipline (Figure 4b).

\section{Partial 3-way Interaction of Elaborateness of Apology, Reputation and Outcome}

Results did not statistically support Hypotheses 6 and 7. Although Hypothesis 7 predicts, under the major outcome, that the positive impact of a simple apology versus no apology is greater when the offender has a good reputation, it does not appear in the sample that when an offender with good reputation went from expressing no apology to simple apology the subjects recommended less discipline $(-=.43$ vs. $\bar{x}=.47)$. However, this trend is consistent with the hypothesis which when the offender with a bad reputation went from expressing no apology to simple apology, the subjects recommended more (Figure 5).

\section{Individual Items of Discipline as Dependent Variables}

\section{Apology-Outcome-Reputation}

Hypothesis 1 predicts that the more elaborate the apology, the less the punishment will be. Only one disciplinary item, Dismiss, showed significance $(F=3.72, p<.05)$. The trend indicates that as the offender engaged in more elaborate apology, the respondents more strongly disagreed with dismissal.

Hypothesis 2 was tested by the main effects of the treatment variable Outcome on six disciplinary items. Results show that items Nothing $(F=11.63, p<.001)$, Suspend $(F=34.96, p<$ $.001)$ and Dismiss $(F=50.97, p<.001)$ showed support for Hypothesis 2, while the rest of the items did not. For the item 


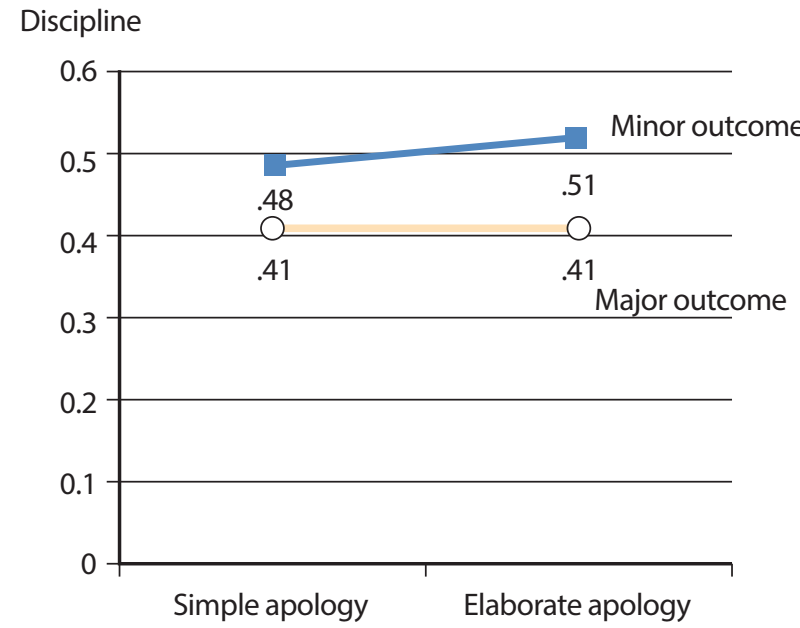

(a) Apology and outcome

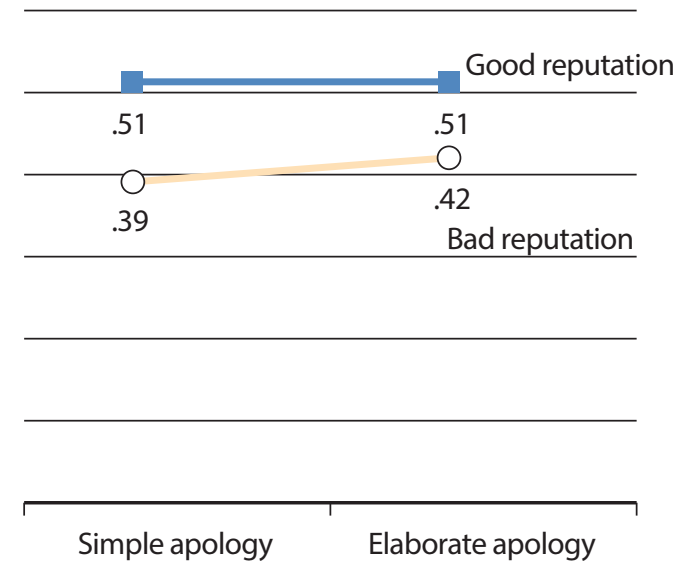

(b) Apology and reputation

Figure 4. Interaction effects of apology with outcome and reputation on discipline.

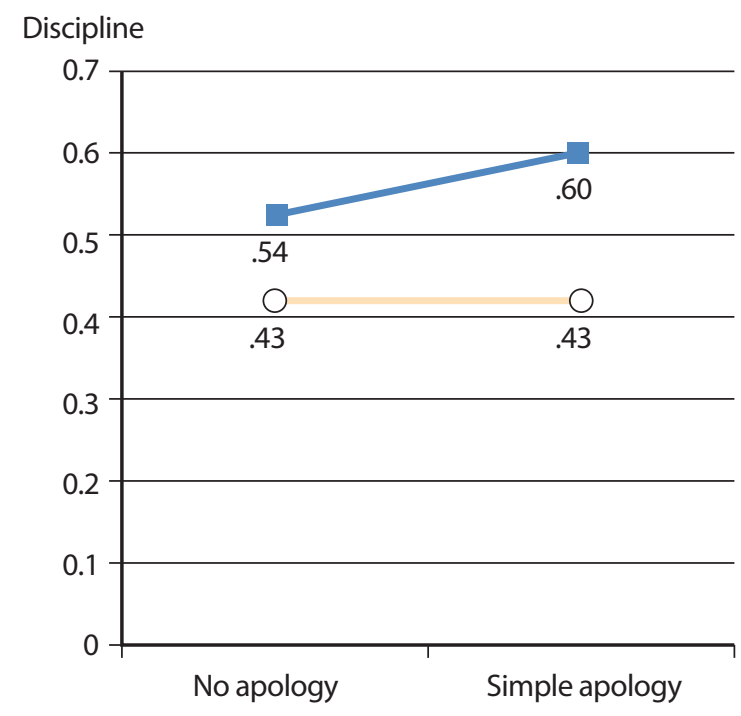

(a) Minor outcome

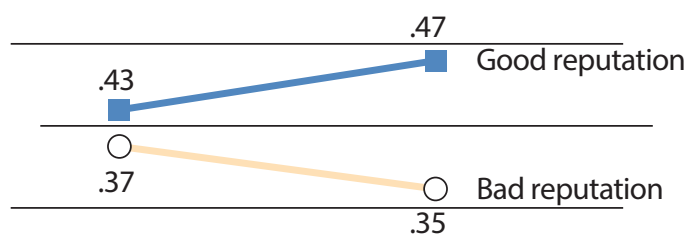

No apology Simple apology

(b) Major outcome

Figure 5. Three-way interaction effect of apology, reputation, and outcomes on discipline.

Nothing, subjects more strongly disagreed with the statement "I would do nothing" by more in the major outcome condition than in the minor. Subjects more strongly disagreed with the statement "I would at least suspend the offender without pay" under the minor outcome $(\bar{x}=3.59)$ than the major outcome condition $(\bar{x}=2.67)$. Lastly, for the disciplinary item Dismiss, the subjects more strongly disagreed with the statement "I would dismiss the offender" under the minor outcome $(\bar{x}=$ $4.28)$ than in the major outcome $(\bar{x}=3.46)$. The trends are consistent with the hypothesis.

Hypothesis 3 predicted that when reputation is favorable, punishment will be less than when reputation is unfavorable. This was tested by the main effects of treatment variable Reputation on the six disciplinary items. Results demonstrate that five items except Oral did show statistical significances.

\section{Elaborateness of Apology with Outcome and Reputation}

Hypothesis 4 predicted that the effects of elaborateness of apology are moderated by severity of outcome, but the results failed to support the hypothesis. Hypothesis 5 predicted that the effects of elaborateness of apology on punishment will be moderated by reputation, but the results also failed to support the hypothesis. 


\section{Partial 3-way Interaction of Elaborateness of Apology, Reputation and Outcome}

Hypothesis 6 predicted the negative impact of elaborate apology to be greater for bad reputation than for good reputation. Only Dismiss $(t[42]=1.72, p<.05)$ supported the hypothesis. As shown in Figure 6, under the minor outcome condition an offender with a good reputation who engaged in elaborate apology $(\bar{x}=.68)$ was less likely to face dismissal than when the offender engaged in simple apology $(\bar{x}=.49)$. However, an offender with a bad reputation who engaged in elaborate apology $(\bar{x}=.99)$ was more likely to face dismissal than the offender who engaged in simple apology $(\bar{x}=1.16)$. The trend for the offender with a bad reputation is consistent with the hypothesis.

Hypothesis 7 predicts, under the major outcome condition, that the positive impact of a simple apology versus no apology is greater when the offender has a good reputation. The results indicate that disciplinary items failed to support the hypothesis.

\section{Discussion}

\section{Effects of Apology on Discipline}

Several studies have shown that expression of apology may lead to more lenient discipline and punishment (Harrell, 1980; Ohbuchi, et al., 1989; Wood \& Mitchell, 1981). Similarly, studies involving law enforcement situations found that there were significantly lower sentences imposed under a remorseful condition than under a nonremorseful condition (Rumsey, 1976) and that offenders who expressed remorse were more likely to be seen as persons who are able to police themselves (Darby \& Schlenker, 1989; Piliavin \& Briar, 1964).

The reasons why this occurs can be speculated on with two complementary explanations. The first is to distinguish between weak and strong motivation for an offender to violate as determined by apology or lack of apology (Schwartz, Kane, Joseph, \& Tedeschi, 1978). Schwartz et al. (1978) suggest that an offender who expresses remorse is demonstrating that, "the actor is less likely to repeat the action" (p. 293). An expression of apology and remorse is a behavioral indication not only that the offender's motive behind the action is weak or transient, but also that the offender does not like her own action. It is unlikely that the behavior will be repeated, so the expression of apology and remorse serves to mitigate punishment. The recommended discipline for remorseful subordinates is significantly less than for those who were not remorseful (Rosen \& Adams, 1974). Conversely, Sykes and Matza (1957) and Gusfield (1963) found that an unrepentant rule breaker is viewed as more likely to repeat a crime (Schwartz et al., 1978).

The second explanation is that apology is an offender's payment for the cost incurred. The violation has taken something away from the offended, so the situation is inequitable, and the offender must pay the "cost" suffered. The offender can restore justice (Hatfield, Walster, \& Walster, 1978) either by making monetary reparation or by emotional reparation such as apology (O’Malley \& Greenberg, 1983). By apology, an offender may be given credit for trying to restore justice. If apologies and remorse are perceived to be sincere, an offended may be obligated by social norms to conclude that the offender's suffering merits relief from sanctions. Within the framework of equity theory, this sequence of apology-forgiveness can be viewed as one way in which an offender can restore equity (Walster, Berscheid, \& Walster, 1973).

Combining both explanations to more fully understand the

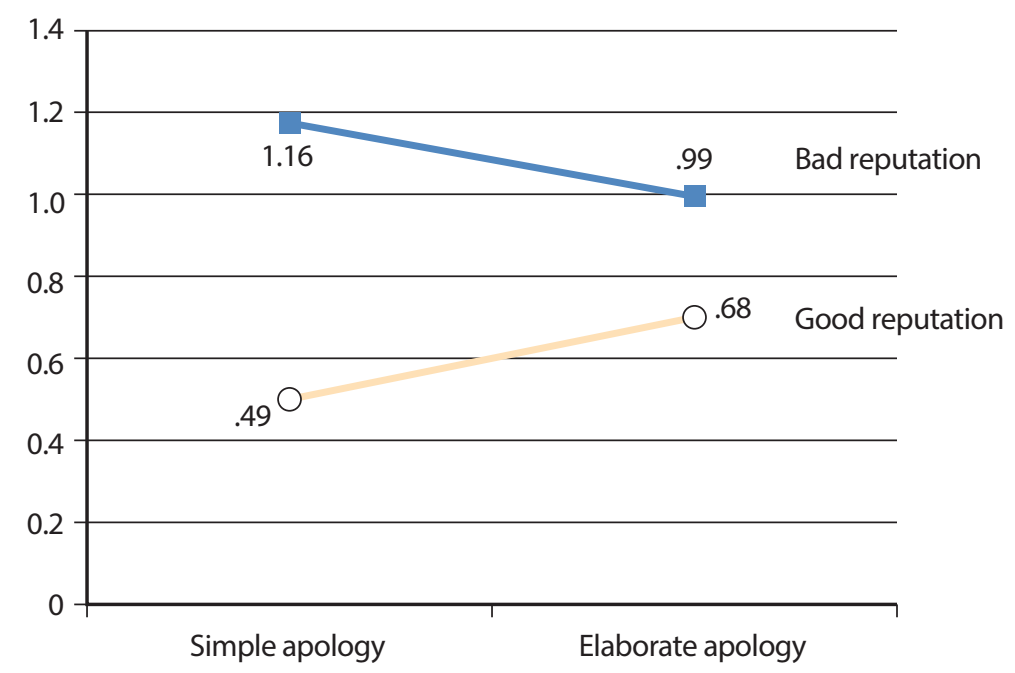

Figure 6. Interaction effect of apology and reputation on dismissal when the outcome is minor. 
effects of apology on discipline, the offended may evaluate both the likelihood of the violation occurring again and the offender's attempted restoration of equity from an inequitable situation (Rosen \& Adams, 1974; Woodyatt \& Wenzel, 2014).

\section{Elaborateness of Apology and Seriousness of Violation}

Schlenker and Darby's (1981) varying degrees of elaborateness can be ordered along a continuum, starting with the least elaborate apologies such as "pardon me," to self-castigation - a much more elaborate expression of self-blame. They found that as the outcome of the violation becomes more serious, the offender's apology gradually becomes more elaborate. Self-castigation is perceived by the offended to involve the most self-blame, followed by requests for forgiveness and expressions of remorse.

Based on the above findings and equity theory, we can surmise that as the seriousness of the violation increases the offender will be required to express more elaborate apology to reduce the punishment. The "appropriate level" of apology is dictated by the severity of the violation. How effective the apology is in reducing the level of punishment appears to be at least in part driven by the severity of the violation. It has yet to be determined how varying degrees of apology affect discipline given differing levels of violation. We can expect that offenders will engage in more elaborate apologies in order to satisfy the greater "payback" demanded by offendeds where the outcome is severe. If the level of apology expressed by the offender does not fit, i.e., is inappropriate given the severity of outcome, then the apology may not be effective in reducing punishment (Lee, 1999).

According to Goffman and Manning (1971) and Schlenker (1980), the components of an apology should be tailored to fit the specific situation. That is, "goodness of fit" is required between the severity of the violation and the elaborateness of apology expressed. A satisfactory apology is one in which the offended perceives the apology to be adequate given the severity of the outcome. If "goodness of fit" is lacking, then the perceived sincerity and credibility of the apology may be jeopardized. In addition to the "goodness of fit," the perception of sincerity may also be significantly moderated by reputation.

\section{Favorableness of Reputation}

"Good reputation" of an employee is defined as "effectiveness as perceived from the perspective of the individual who [is] satisfied with the job behavior and activities exhibited by the employee" (Tsui, 1984). An explanation for the argument can be made from a theoretical perspective by integrating both equity and attribution theories. These may further support the argument that an offender's reputation will either enhance or undermine apology.
Equity theory can be expanded to take into consideration past exchanges between the offender and the other employees in the workplace, which may influence how future exchanges are viewed. From attribution theory, one can argue that an offense committed by an individual with a bad reputation may be internally attributed. Such an offender will be viewed as more likely to repeat offenses given her past deviant behaviors. In contrast, an offender with a good reputation benefits from the perception that an expression of apology is consistent with her reputation (Dugan, 1989; Heneman, Greenberger, \& Anonyuo, 1989; Martinko \& Gardner, 1987; Overall, Sibley, \& Travaglia, 2010).

\section{Findings Compared with Previous Studies}

Overall, this study provided empirical evidence to partially support the claim that apology leads to less punishment. In particular, the supplemental variable Dismiss was significant. For the remaining supplemental variables and the main dependent variable Discipline, the level of discipline suggested remained similar regardless of varying degrees of apology. The seriousness of the offense did lead to significant differences in the discipline recommended (Darby \& Schlenker, 1982).

Reputation also plays a role in determining the level of discipline. Only the supplemental variable Nothing failed to support Hypothesis 3. The main dependent variable Discipline and all other remaining supplemental variables showed strong support for this hypothesis. No variables showed significance for Hypothesis 4 .

Although this study found limited support for the main effect involving reputation, when the interactive effects of offender's reputation and the elaborateness of the offender's apology were examined, the results were insignificant. This study also failed to support the interactions involving apology, reputation and outcome. When the offender's reputation is "good," even an excessive apology was not expected to be viewed as manipulative because the offender's good reputation is expected to enhance the apology. No support was found for this argument. The results indicated no significant difference between offenders with good and bad reputations when they expressed inadequate or partial apology.

The presentation of the interaction of three variables in an attempt to produce "goodness of fit" on the level of punishment resulted in findings that fail to support the past literature. Past studies have supported the view that the expression of apology leads to less punishment. But several researchers, more consistent with the findings of this study, have argued that there are many instances in which the expression of apology does not lead to less punishment (O’Malley \& Greenberg, 1983; Schlenker, 1980).

Rather practically, the findings of this study can be implied 
to managerial practices such as the employer-customer interface. As a service recovery strategy, financial compensation combined with an apology, directly reduce the occurrence of retaliation, as well as indirectly reduce retaliation through the mediating effects of customer anger (Keeffe, Russel-Bennet, \& Tombs, 2008).

\section{Limitations and Future Directions}

While the present study addresses an omission in the literature, it does so with two primary limitations: sample and scenario. Undergraduate students tend to lack extensive work experience, especially supervisory experience; thus, their decisions may not have been reflective of a typical manager. The concern with the scenarios used for this study is one of realism. Given that the offended's reaction involves forgiveness, a greater emotional involvement of the subject may be required. It is quite possible that the reactions of the subjects would have differed if they had had a relationship with the offender.

Based on equity theory, this study attempted to show that the possible reason for the inconsistencies in the effect of apology on reducing punishment may have been due to lack of fit between the apology expressed by the offender and the seriousness of the offense. It may be that an alternative framework must be developed to more consistently determine the relationship between apology and discipline.

\section{Conclusion}

This study analyses the relationship between elaborateness of apology and subsequent disciplinary action considering different levels of outcome severity and favorable reputation. Although there was no statistically significant support for apology's effect on the composite measure of discipline and interactions involving apology, six separate items of disciplinary action partially supported hypotheses. There was also support for the effects of severity of outcome and reputation of the offender on the level of disciplinary action recommended. It was hoped that the present study would begin to shed some light on the issue of under what circumstances the apology is effective in reducing punishment. The results of the present study demonstrate that the issue of apology's effect on discipline is more complex than once thought. Thus greater consideration should be taken in efforts to achieve a better understanding of its effects.

\section{Acknowledgement}

This research was funded by the International Scholar Program from Kyung Hee University, Seoul, Korea.

\section{References}

Aronfreed, J. (1968). Conduct and conscience: The socialization of internalized control over behavior. New York, NY: Academic Press.

Bataineh, R. F., \& Bataineh, R. F. (2006). Apology strategies of Jordanian EFL university students. Journal of Pragmatics, 38(11), 1901-1927.

Burton, R. V., MacCoby, E. E., \& Allinsmith, W. (1961). Antecedents of resistance to temptation in four-year-old children. Child Development, 32(4), 689-710.

Christopher, A. N., Marek, P., \& May, J. C. (2003). The protestant work ethic, expectancy violations, and criminal sentencing 1. Journal of Applied Social Psychology, 33(3), 522-535.

Darby, B. W., \& Schlenker, B. R. (1982). Children's reactions to apologies. Journal of Personality and Social Psychology, 43(4), 742-753.

Darby, B. W., \& Schlenker, B. R. (1989). Children's reactions to transgressions: Effects of the actor's apology, reputation and remorse. British Journal of Social Psychology, 28(4), 353-364.

Dugan, K. W. (1989). Ability and effort attributions: Do they affect how managers communicate performance feedback information? Academy of Management Journal, 32(1), 87-114.

Fehr, R., Gelfand, M. J., \& Nag, M. (2010). The road to forgiveness: A meta-analytic synthesis of its situational and dispositional correlates. Psychological Bulletin, 136(5), 894-914.

Gavin, M. B., Green, S. G., \& Fairhurst, G. T. (1995). Managerial control strategies for poor performance over time and the impact on subordinate reactions. Organizational Behavior and Human Decision Processes, 63(2), 207-221.

Goffman, E., \& Manning, P. (1971). Relations in public. New York, NY: Harper Colophon Books.

Gusfield, J. (1963). Symbolic crusade: Status politics and American temperance movement. Urbana, IL: University of Illinois Press.

Harrell, W. A. (1979). Aggression against a remorseful wrongdoer: The effects of self-blame and concern for the victim. The Journal of Social Psychology, 107(2), 267-275.

Harrell, W. A. (1980). Retaliatory aggression by high and low Machiavellians against remorseful and non-remorseful wrongdoers. Social Behavior and Personality, 8(2), 217-220.

Hatfield, E., Walster, E. H., \& Walster, G. W. (1978). Equity: Theory and research. Boston, MA: Allyn \& Bacon.

Heneman, R. L., Greenberger, D. B., \& Anonyuo, C. (1989). Attributions and exchanges: The effects of interpersonal factors on the diagnosis of employee performance. Academy of Management Journal, 32(2), 466-476.

Jones, E. E., \& Wortman, C. B. (1973). Ingratiation: An attributional approach. Morristown, NJ: General Learning Press. 
Karremans, J. C., \& Van Lange, P. A. M. (2004). Back to caring after being hurt: The role of forgiveness. European Journal of Social Psychology, 34(2), 207-227.

Keeffe, D. A., Russell-Bennett, R., \& Tombs, A. (2008). Customer retaliation at the employee-customer interface. Journal of Management \& Organization, 14(4), 438-450.

Langer, E. J. (1978). Rethinking the role of thought in social interaction. In J. H. Harvey, W. Ickes, \& R. F. Kidd (Eds.), New directions in attribution research (pp. 35-58). Hillsdale, NJ: Erlbaum.

Lee, J. C. (1999). The influence of post-transgression behavior: An interplay between elaborateness of apology and the managerial disciplinary action. Academy of Managerial Communications Journal, 3(2), 1-29.

Leunissen, J. M., De Cremer, D., \& Reinders Folmer, C. P. (2012). An instrumental perspective on apologizing in bargaining: The importance of forgiveness to apologize. Journal of Economic Psychology, 33(1), 215-222.

Martinko, M. J., \& Gardner, W. L. (1987). The leader/member attribution process. Academy of Management Review, 12(2), 235-249.

Ohbuchi, K., Kameda, M., \& Agarie, N. (1989). Apology as aggression control: Its role in mediating appraisal of and response to harm. Journal of Personality and Social Psychology, 56(2), 219-227.

O’Malley, M. N., \& Greenberg, J. (1983). Sex differences in restoring justice: The down payment effect. Journal of Research in Personality, 17(2), 174-185.

Overall, N. C., Sibley, C. G., \& Travaglia, L. K. (2010). Loyal but ignored: The benefits and costs of constructive communication behavior. Personal Relationships, 17(1), 127-148.

Piliavin, I., \& Briar, S. (1964). Police encounters with juveniles. American Journal of Sociology, 70(2), 206-214.

Rosen, B., \& Adams, J. S. (1974). Organizational coverups: Factors influencing the discipline of information gatekeepers. Journal of Applied Social Psychology, 4(4), 375-384.

Rosen, B., \& Jerdee, T. H. (1974). Factors influencing disciplinary judgments. Journal of Applied Psychology, 59(3), 327-331.

Rumsey, M. C. (1976). Effects of defendant background and remorse on sentencing judgments. Journal of Applied Social Psychology, 6(1), 64-68.

Schlenker, B. R. (1980). Impression management: The self-concept, social identity, and interpersonal relations. Monterey, CA: Brooks/ Cole.

Schlenker, B. R., \& Darby, B. W. (1981). The use of apologies in social predicaments. Social Psychology Quarterly, 44(3), 271-278.

Schumann, K. (2014). An affirmed self and a better apology: The effect of self-affirmation on transgressors' responses to victims. Journal of Experimental Social Psychology, 54, 89-96.

Schwartz, G. S., Kane, T. R., Joseph, J. M., \& Tedeschi, J. T. (1978). The effects of post-transgression remorse on perceived aggression, attributions of intent, and level of punishment. British Journal of Social and Clinical Psychology, 17(4), 293-297.

Sykes, G. M., \& Matza, D. (1957). Techniques of neutralization: A theory of delinquency. American Sociological Review, 22(6), 664670.

Tsui, A. S. (1984). A role set analysis of managerial reputation. Organizational Behavior and Human Performance, 34(1), 64-96.

Walster, E., Berscheid, E., \& Walster, G. W. (1973). New directions in equity research. Journal of Personality and Social Psychology, 25(2), 151-176.

Wheeler, H. N. (1985). Industrial conflict: An integrative theory. Columbia, SC: University of South Carolina Press.

Wood, R. E., \& Mitchell, T. R. (1981). Manager behavior in a social context: The impact of impression management on attributions and disciplinary actions. Organizational Behavior and Human Performance, 28(3), 356-378.

Woodyatt, L., \& Wenzel, M. (2014). A needs-based perspective on self-forgiveness: Addressing threat to moral identity as a means of encouraging interpersonal and intrapersonal restoration. Journal of Experimental Social Psychology, 50, 125-135. 